\title{
Influence of Technological Parameters on the Emision on DLP 3D Printing Process
}

\author{
MIRCEA DORIN VASILESCU* \\ Politehnica University Timisoara, 2 Victoriei Sq., 300006, Timisoara, Romania
}

\begin{abstract}
The present work addresses the issue of emissions requires it made in resin polymerization processes at $3 D$ digital light process $(D L P)$ printing. From an emission point of view, both particulate and chemical emissions are analysed in the form of gases during the DLP printing process. In the paper, we present first the element, which are study. In second part of the paper, we presented the printer, material for printing, measuring apparatus for emission and measurement methodology. In the three part of paper, we made the determinations for gas emissions. Will follow the determinations for particulate emissions. In the final chapter, the data generated by the printing emissions related to the problems specific to the laboratory activity and it has made the specific conclusion in rapport with the printing process.
\end{abstract}

Keywords: 3D printing; emission particles; air pollution, resin material, DLP printing

\section{Introduction in emision for 3D printing}

In the process of technological realization of components through 3D printing, an important component is the protection of the environment from the space in which the technological process are developed. Several studies conducted for making component with thermoplastic process determinate the emission. Some of these printing materials affected the environment. For PLA type material re made study in [1,3] and/or other to ABS [2, 6] material. Different types of materials analysed comparatively $[4,5]$. For the study of emissions in the 3D printing process on the DLP principle, we made a study to follow both the print process and post print phases. In the study were followed both the elements specific to temperature and humidity in the printing process and the components of gaseous and particulate emissions emitted. For particle it is determinate the PM2,5 (Fine Particulate Matter) and PM10 (Coarse Particulate Matter) of emission. For air it is determinate the TVOC (total volatile organic compounds) and HCHO (Formaldehyde). The AQI air is determinate in the same time.

Considerations on the printer, matherial for printing and aparat for determineted of emision for $3 D$ printing

For the printing are used a 3D printer type Anycubic Photon (Figure 1.). The used printer are printing probe for study the modification of rectangular parts in 3D printing process.

For printing, we used a specific resin for printing (Figure 2.). It is a green transparent resin type Anycubic.

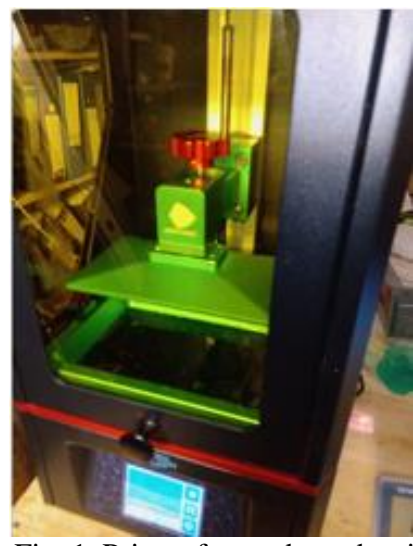

Fig. 1. Printer for made probes in the 3D printed process

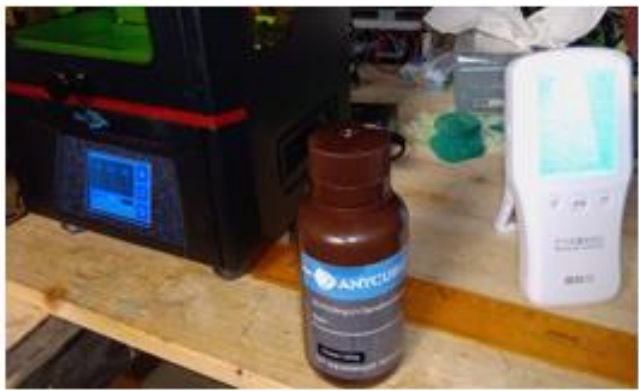

Fig. 2. Printer, resin and apparatus for made probes in the $3 \mathrm{D}$ printed process

For measurement of the emission an apparatus are used. It can determine all the elements mentioned in the first part of the work (Figure 3.). It is possible to see that the apparatus JBL-B600 [7] ensures the determination of the intended emission elements.

For made the measurement are designed which was positioned at a distance of $160 \mathrm{~mm}$ from the 3D printer (Figure 4.). The printer although it is equipped with a ventilation and filtration system emits unfiltered elements in the atmosphere. This is the principal motive for this experiment.

*email:mircea.vasilescu@upt.ro 


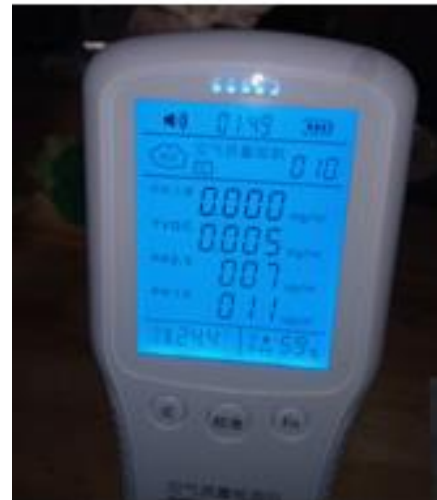

Fig. 3. Apparatus for determinate emission in the $3 \mathrm{D}$ printed process

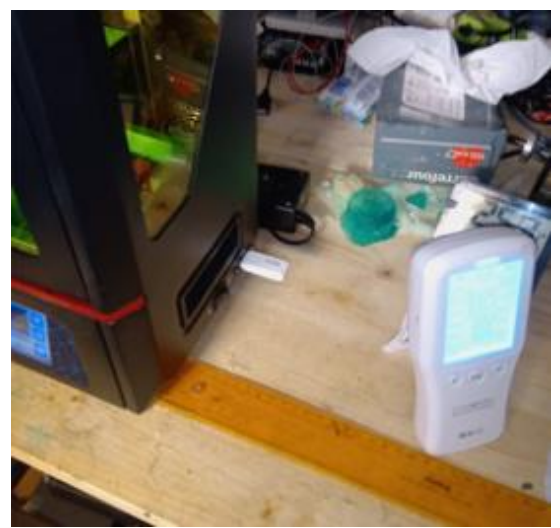

Fig. 4. System for determinate emission in the $3 \mathrm{D}$ printed process

With these defined elements, we are conduct the process of made the experiment and processing the data obtained by measurements performed during the printing process.

With these defined elements, we made the experiment. For processing of data obtained by measurements performed during the process of processing of the problems. It should note that in the case of DLP but also for the SLA, process has two distinct phases. The first phases is the effective print. Second, one is the cleaning process of probe. In both phases, we made the measurement of emission.

\section{Considerations on gas emision in the $3 D$ printing DLP process}

The first of the analysed and determined elements was that of HCHO-type emissions. In the printing process we determinate the emission at approximately equal time intervals of 2 to 5 minutes throughout the print process. Based on the measured values made we generated the specific graphics for linear and polynomial regression equation. The equations are solve with EXCEL 2013 educational solution. It is possible to see that for linear regression the R solve value is smaller than 0.95 (Figure 5.), but for polynomial regression equation 4 degree (Figure 6.) the $\mathrm{R}$ value are 0.952 which is in the value domain for trust.

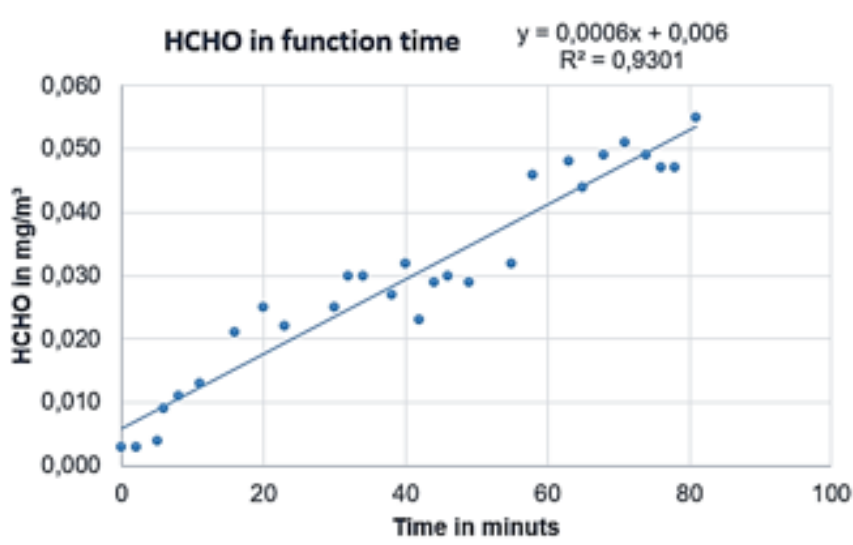

Fig. 5. Linear representation for $\mathrm{HCHO}$ emission on 3D printed part

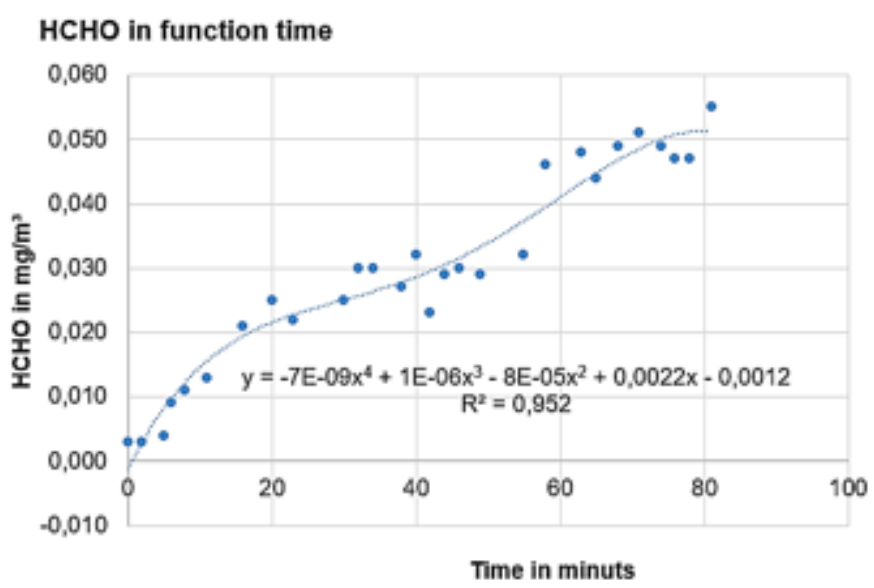

Fig. 6. Polynomial representation for $\mathrm{HCHO}$ emission on 3D printer part

In the analysis of the representation of graphic values data, it is possible to conclude that the proxy linear data arrangement observed in closed escape for printing for $\mathrm{HCOH}$. The maximum value in 80 minute for printing are 0.055 milligrams in meter cubic.

The second air component determinate, analysed and plotting was that of TVCO-type emissions. In the printing process we determinate the emission at approximately equal time intervals of 2 to 5 minutes throughout the print process. Based on the measured values made we generated the specific graphics for linear and polynomial regression equation. The equations are solve with EXCEL 2013 educational solution. It is possible to see that for linear regression the R solve value is smaller than 0.95 (Figure 7.), but for polynomial regression equation 3 degree (Figure 8.) the $\mathrm{R}$ value are 0.9614 which is in the value domain for trust.

In the analysis of the representation of graphic values data, it is possible to conclude that the proxy linear data arrangement observed in closed escape for printing for TVOC. This value are proxy similar like dispose of $\mathrm{HCOH}$ value. The maximum value in 80 minute for printing are 0.363 milligrams in meter cubic. This maximum is greater than $\mathrm{HCOH}$ value by seven or value. 


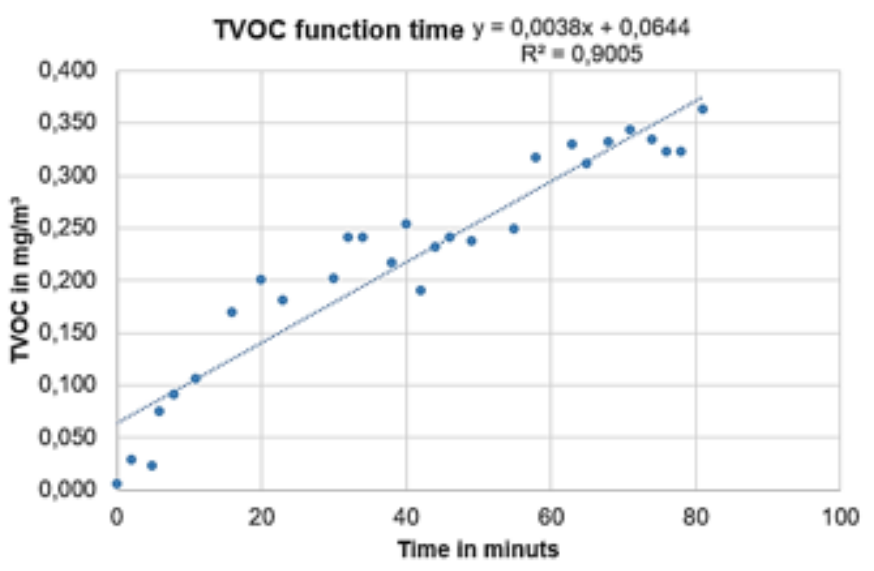

Fig. 7. Linear representation for TVOC emission on 3D printed part

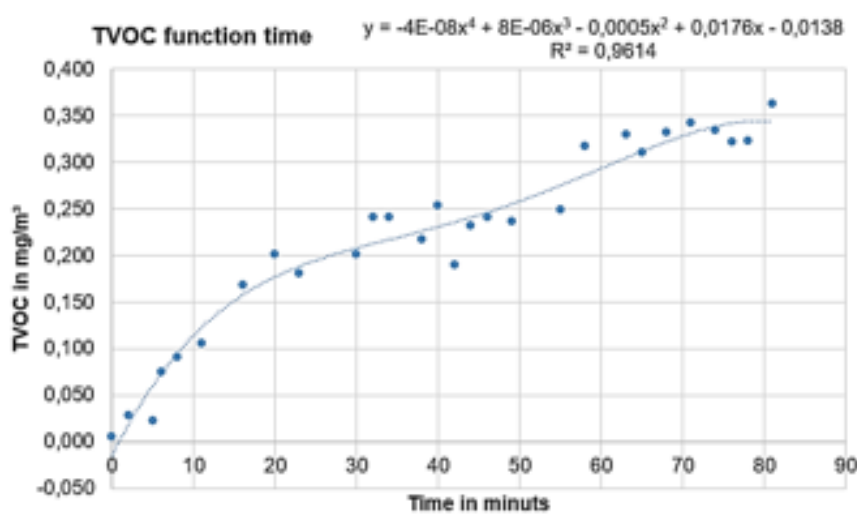

Fig. 8. Polynomial representation for TVOC emission on 3D printed part

If we take as a reference the information in $[8,9]$ then it can be observed that gas emission limits are half the reference value for $\mathrm{HCHO}(0.100 \mathrm{mg} / \mathrm{m} 3)$. The emission value is less but very close to that for ABS $(0.055 \mathrm{mg} / \mathrm{m} 3 \mathrm{at} 0.069 \mathrm{mg} / \mathrm{m} 3)$. If we compare the values obtained for TVOC it is possible to see that compared to the reference $(0.5 \mathrm{mg} / \mathrm{m} 3)$ the maximum, value obtained by $(0.363 \mathrm{mg} / \mathrm{m} 3)$ is almost twice as low. If we compare the value for resin with that for ABS $(0.635 \mathrm{mg}$ $/ \mathrm{m} 3$ ), it may be observed to be less than twice.

From the analysis carried out it is possible to say that from the point of view of gas emissions for resin the risks are lower than in the case of printing for ABS. However, it is possible to say that for laboratory work, resin printing we recommended to working in closed systems with additional filtering and ventilation elements.

\section{Considerations on particles emision in the $3 D$ printing DLP process}

The first of the analysed and determined elements was that of PM 2.5 particle emissions. In the printing process we determinate the emission at approximately equal time intervals of 2 to 5 minutes throughout the print process. Based on the measured values made we generated the specific graphics for linear and polynomial regression equation. The equations are solve with EXCEL 2013 educational solution. It is possible to see that for linear regression the $\mathrm{R}$ solve value is smaller than 0,95 (Figure 9.), but for polynomial regression equation 4 degree (Figure 10.) the $\mathrm{R}$ value are 0.4241 which is smaller than the value domain for trust equation.

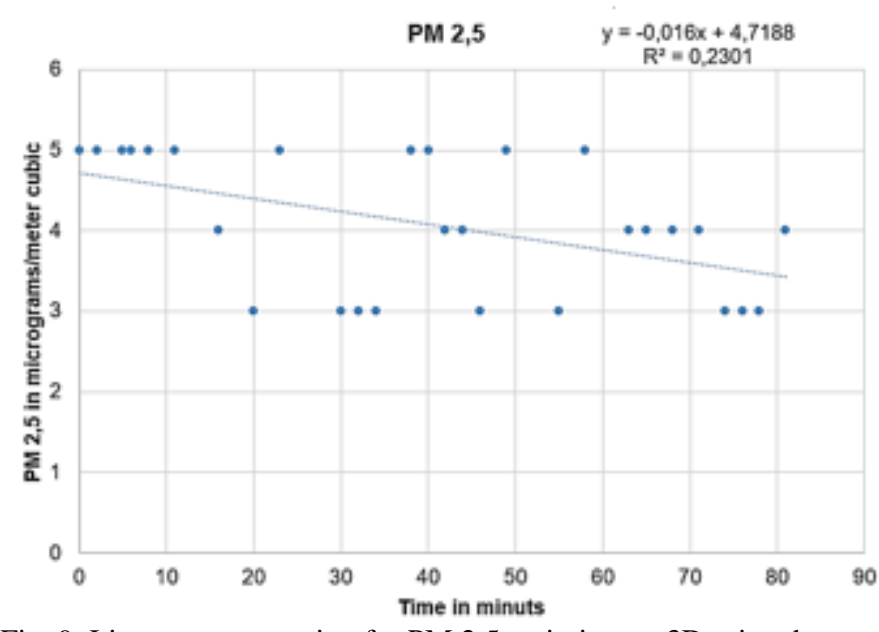

Fig. 9. Linear representation for PM 2.5 emission on 3D printed part

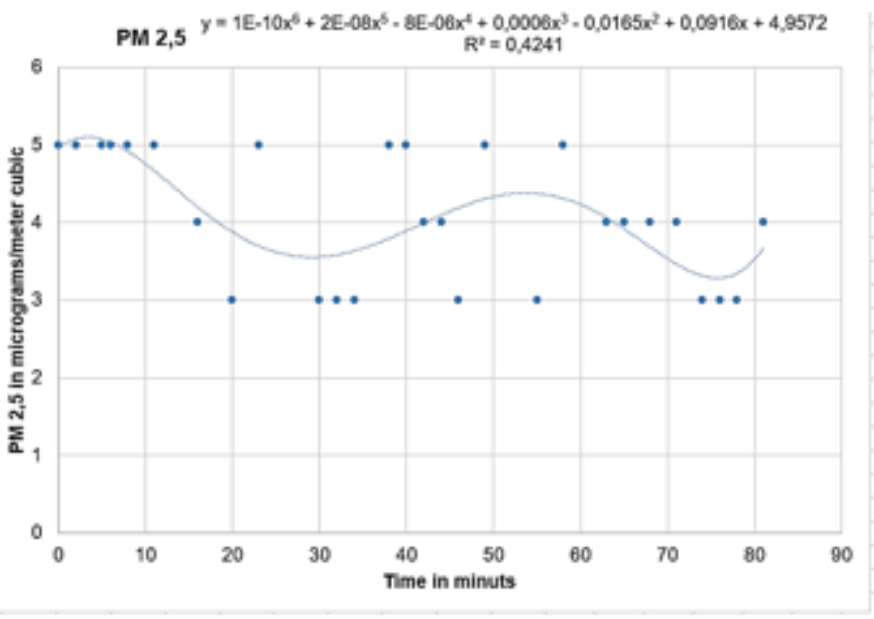

Fig. 10. Polynomial representation for PM 2.5 emission on 3D printed part

In the analysis of the representation of graphic values data, it is possible to conclude that the distribution of the data value are dispose between a minimum $3 \mu \mathrm{g} / \mathrm{m}^{3}$ and a maximum of $5 \mu \mathrm{g} / \mathrm{m}^{3}$ value with alternant period of time of emission. The slightly decreasing trend for PM 2.5 can be observed during the resin printing process. The maximum emission value for PM $2.5\left(5 \mu \mathrm{g} / \mathrm{m}^{3}\right)$ is less than the reference value $\left(55.5 \mu \mathrm{g} / \mathrm{m}^{3}\right)$ about 11 times.

The second of the analysed and determined elements was that of PM 10 particle emissions. In the printing process we determinate the emission at approximately equal time intervals of 2 to 5 minutes throughout the print process. Based on the measured values made we generated the specific graphics for linear and polynomial regression equation. The equations are solve with EXCEL 2013 educational solution. It is possible to see that for linear regression the R solve value is smaller than 0.95 (Figure 11), but for polynomial regression equation 4 degree (Figure 12.) the $\mathrm{R}$ value are 0.4276 which is smaller than the value domain for trust equation. 


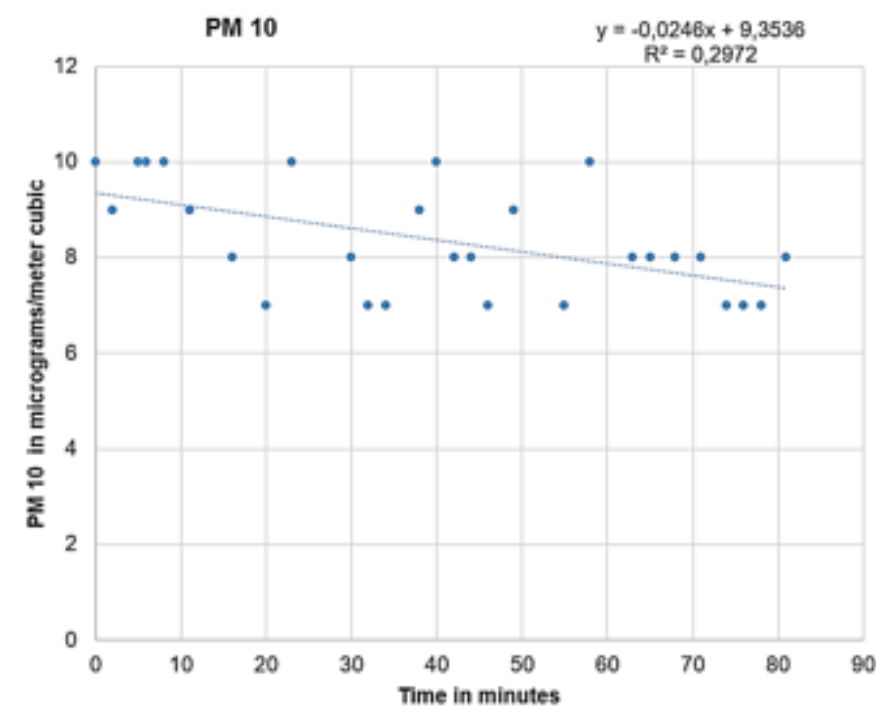

Fig. 11. Linear representation for PM 10 emission on 3D printed part

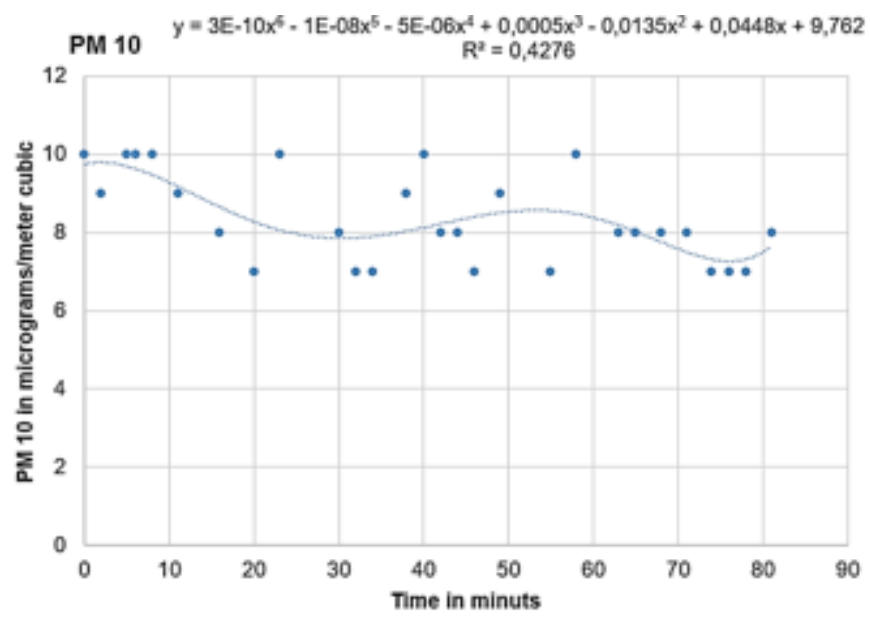

Fig. 12. Polynomial representation for PM 10 emission on 3D printed part

In the analysis of the representation of graphic values data, it is possible to conclude that the distribution of the data value are dispose between a minimum $7 \mu \mathrm{g} / \mathrm{m}^{3}$ and a maximum of $10 \mu \mathrm{g} / \mathrm{m} 3$ value with alternant period of time of emission. The slightly decreasing trend for PM 10 it is possible to see during the resin printing process.

If we take as a reference the information in $[8,10]$ then it can be observed that PM 10 limits are $10 \mu \mathrm{g} / \mathrm{m}^{3}$. The reference value for PM 10 is double like PM $2.5\left(55,5 \mu \mathrm{g} / \mathrm{m}^{3} * 2=111 \mu \mathrm{g} / \mathrm{m} 3\right)$. The emission particle value is less but very close to that for ABS $\left(76 \mu \mathrm{g} / \mathrm{m}^{3}\right)$ about 7 times.

To highlight the determined values we will present two of the measurements made. The first one on the left (Figure 13.) for the beginning of the processing. The second one on the right (Figure 13.) for the end of the processing. It is possible to see that changing temperature and humidity during the process is insignificant as a value.
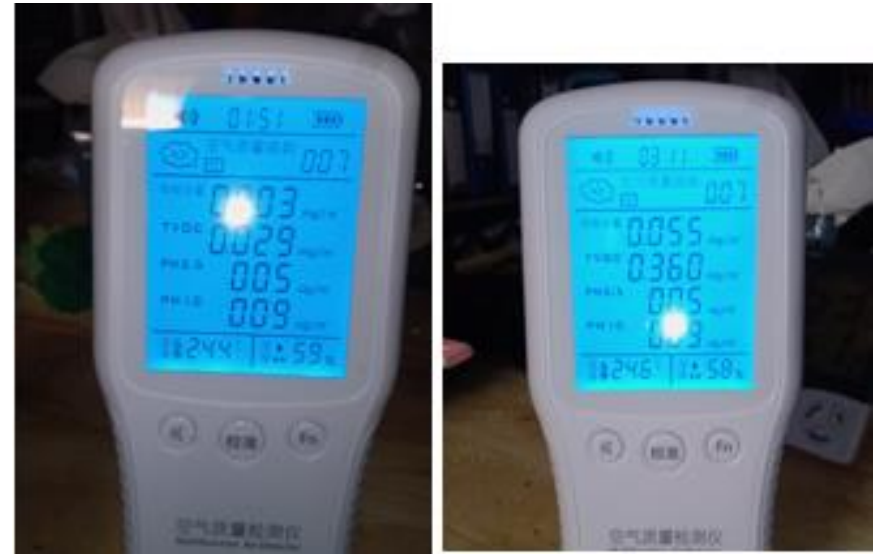

Fig. 13. Value for emission on 3D printed part left start print, right final print
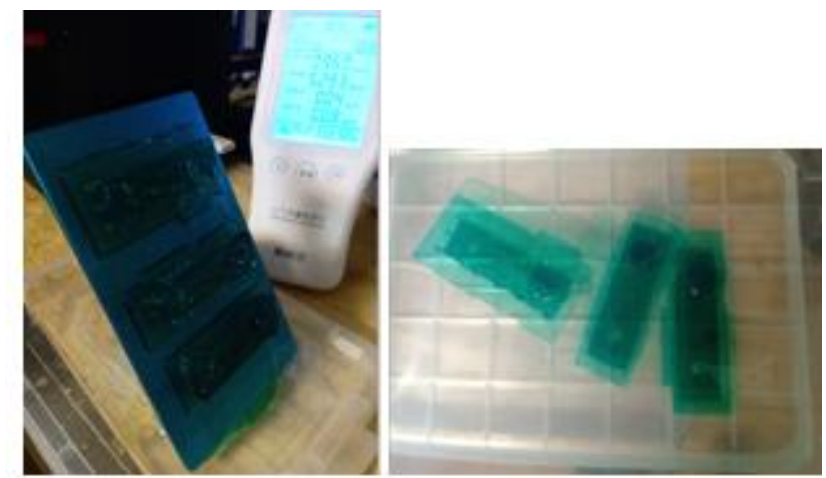

Fig. 14. Probes with apparatus of measure emission in left part and probes to cleaning in right part

\section{Considerations on emision in the postprintig DLP process}

The 3D resin printing process has a subsequent phase of dissolution of adherent resins on the surface of the printing process is carried out (Figure 14.). On the left side of (Figures 14.), it is possible to see the emission measuring apparatus and in front at left the printed probes. The plate with 3D printed probes after extracting the plate from the printer presented in figure. In the right part of the aforementioned figure, it is possible to observe, the probes introduced in the cleaning medium. Due to its chemical composition and emitted emissions, large increases in gaseous values are produce and put in (Table 1.). The values coloured in the table in yellow are the ones from the completion of the print. 
Table 1

VALUE FOR EMISSION HCOH AND TVOC AFTER PRINTING AT DIFFERENT TIME FROM STOP PRINTING

\begin{tabular}{|l|r|r|r|r|r|r|r|r|r|}
\hline Time & 4 & 10 & 17 & 18 & 20 & 22 & 27 & 29 & 30 \\
\hline HCHO & 0,055 & 0,058 & 0,062 & 0,780 & 0,941 & 2,888 & 2,884 & 2,888 & 0,147 \\
\hline TVOC & 0,360 & 0,402 & 0,446 & 3,871 & 5,127 & 9,999 & 9,999 & 9,999 & 0,785 \\
\hline
\end{tabular}

The graphical representation of the data from the table mentioned can be seen in (Figure 15.) with the specific regression equations. Both types of emissions present increased values in the portion of time between 20 minutes and 30 minutes after extracting the samples from the printer. For $\mathrm{HCOH}$ the value of $2.888 \mathrm{mg} / \mathrm{m}^{3}$ is 29 times higher than the allow ability limit. For TVOC the value of $9.999 \mathrm{mg} / \mathrm{m}^{3}$ is 19 times higher than the allow ability limit.

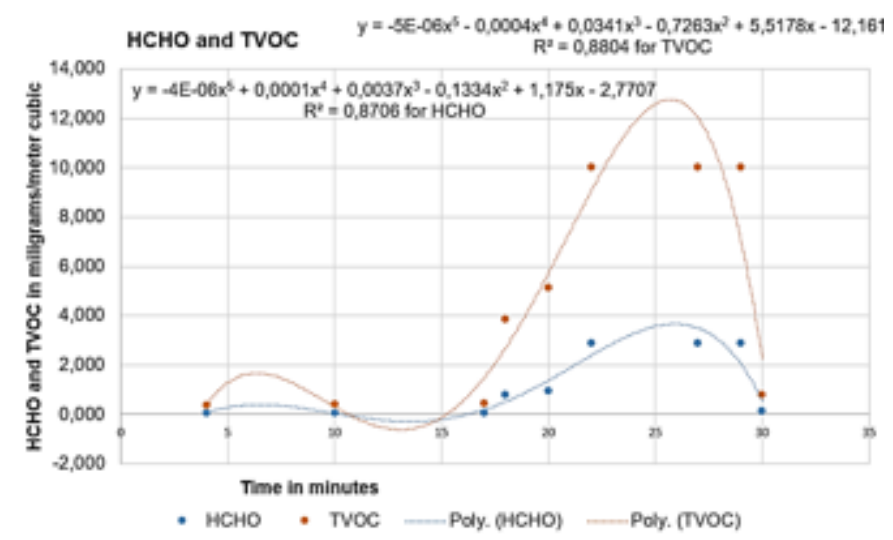

Fig. 15. Polynomial representation for $\mathrm{HCOH}$ and TVOC emission after 3D printed parts

Due to the observation presented, we recommended that the cleaning process carried out in outdoor spaces or wellventilated enclosures to reduce the harmful effects of emissions. The values coloured in the table in yellow are the ones from the completion of the print.

Table 2

VALUE FOR EMISSION PM 2.5 AND PM 10 AFTER PRINTING AT DIFFERENT TIME FROM STOP PRINTING

\begin{tabular}{|l|r|r|r|r|r|r|r|r|r|}
\hline Time & 4 & 10 & 17 & 18 & 20 & 22 & 27 & 29 & 30 \\
\hline PM2.5 & 5 & 3 & 4 & 5 & 4 & 5 & 6 & 5 & 5 \\
\hline PM10 & 9 & 7 & 8 & 9 & 8 & 9 & 10 & 9 & 9 \\
\hline
\end{tabular}

Not the same effect it is possible to see on the part of particle emissions from (Table 2.). Particle emission are keep it in the same value like printing part.

\section{Conclusions}

The present study intended to be a beginning of research on the generation of study emission in 3D printing process.

From the analysis carried out it is possible to say that from the point of view of gas emissions for resin the risks are lower than in the case of printing for ABS. However, it is possible to say that for laboratory work, resin printing we recommended to working in closed systems with additional filtering and ventilation elements.

The study identified the mandatory restrictions to consider for the use of technology in student laboratory conditions and not only.

It is important to noted that many studies address this 3D resin printing process especially from the medical field [11 15] but also from the industrial domain [16] why the work done is of major importance in relation to the working conditions in these areas

Acknowledgements: It should be noted that this study was conducted on their own authors and not part of any research program funded from national or international financial fund.

\section{References}

1.DENG, Y., CAO, S-J, CHEN, A., GUO, Y., The impact of manufacturing parameters on submicron particle emissions from a desktop 3D printer in the perspective of emission reduction, Building and Environment, Volume 104, 2016, pp 311-319

2.STEINLE, P., Characterization of emissions from a desktop 3D printer and indoor air measurements in office settings, Journal of Occupational and Environmental Hygiene, Volume 13, Issue 2, 2016, pp. 121-132

3.STEPHENS, B, AZIMI, P., EL ORCHA, Z., RAMOS, T., Ultrafine particle emissions from desktop 3D printers, Atmospheric Environment, Volume 79, 2013, pp. 334-339

4.*** - http://diy3dtech.com/3d-printing-and-air-quality-risks/, 2019 
5. PASCU, N. E., ARION, A.F., DORESCU, T., CARUTASU N. L., Fused deposition modeling design rules for plastics, Mat.Plast., 52, no. 2, 2015, pp. 141-143

6. BYRLEY P, GEORGE B.J, BOYES WK, ROGERS K., Particle emissions from fused deposition modeling 3D printers: Evaluation and metaanalysis, Sci Total Environ, DOI:10.1016/j.scitotenv.2018.11.070, 2019, pp. 395-407,

7.***https://www.ebay.com/p/8in1-Air-Quality-Monitor-Pm10-Pm2-5-Formaldehyde-HCHO-TVOC-LCD-Digital-Detector/18030108267, 2019. 8.***http://diy3dtech.com/wp-content/uploads/2018/05/AirQ_01.png, (2019).

9.DAVIS, A.Y., ZHANG, Q., WONG, J.P.S., WEBERB, R.J., BLACK, M.S., Characterization of volatile organic compound emissions from consumer level material extrusion 3D printers, Building and Environment, Volume 160, 2019,

10.*** https://www.who.int/en/news-room/fact-sheets/detail/ambient-(outdoor)-air-quality-and-health, 2019

11.VitAlARIU, A. TATARCIUC, M., LUCA, O., HOLBAN CIOLOCA, C., BULANCEA, B., AUNGURENCEI, A., AUNGURENCEI, O., RAFTU, G., DIACONU POPA D., Structural and Thermal Changes in Dental Resins Enriched with Silver Nanoparticles, Rev. Chim..(Bucharest), 70, no. 2, 2019, p. $591-595$.

12.DAWOD, N., FLORESCU, A., ANTONIAC, I. V., STOIA, D. I., HANCU, V., BICLESANU F. C., - The Fea Study of the Biomecanic Behavior Of Canine Reconstructed With Composite Resin, Rev. Chim. (Bucharest), 70, no. 2, 2019, p. 2456 - 2462

13.BOLCU, D., STANESCU, M. M., CIUCA, I., DINITA, A., ROSCA, A., ROSCA, D., Experimental Research Into the Mechanical Behaviour of Dammar and Sandarac - Based Bio Resins, Mat. Plast., 56 , no. 1, 2019, p.1 - 5

14.VASILESCU, E., DOCAN, A., VASILESCU,V. G., POPA, C. L., IONEL, D. C., MUNTENITA, C., Experimental Study on the Improvement of the Use of Diacrylic Composite Resins in Restorative Dentistry by Compensatory Techiniques, Mat. Plast., 56 no. 2, 2019, p.378 - 381

15.MELESCANU-IMRE, M., PANTEA, M., TOTAN, A., TANCU, A.M.C., GREABU, M., TOTAN, C., SPINU T. C., Biochemical Interactions Between Polymeric Resins Used for Occlusal Splints and Saliva a Pilot Study Comparing the Cad/Cam Technology and the Conventional Approach, Mat. Plast., 56, no. 2, 2019, p.409-412

16.VASILESCU, M.D., Constructiv and Technological Consideration on the Generation of Gear Made by the DLP 3D-Printed Methode, Mat. Plast.., 56, no. 2, 2019, p. $440-444$

Manuscript received: 30.10 .2019 